\title{
Psychometric properties of the incontinence utility index among patients with idiopathic overactive bladder: data from two multicenter, double-blind, randomized, Phase 3, placebo- controlled clinical trials
}

\author{
Nacho Castejón ${ }^{1 *}$, Kristin Khalaf², Quanhong $\mathrm{Ni}^{3}$, Jesús Cuervo ${ }^{1}$ and Donald L Patrick ${ }^{4}$
}

\begin{abstract}
Background: Overactive bladder is a prevalent and burdensome condition. Generic utility measures may fail to reflect its full impact on patients' health status. The Incontinence Utility Index (IUI) is a community-based preference index derived from the Incontinence Quality of Life Questionnaire (I-QOL) developed to value health states related to urinary symptoms in patients with neurogenic detrusor overactivity. This study assessed the measurement properties of the IUI in patients with idiopathic overactive bladder (OAB).

Methods: Data were used from two clinical trials which recruited patients with $O A B$ whose symptoms were inadequately managed with $\geq 1$ anticholinergic medication. Psychometric evaluation included: Differential Item Functioning (DIF) analysis, concordance between I-QOL and IUI (Intraclass correlation coefficient [ICC], criterion and convergent validity according to relevant patient reported outcomes and clinical variables (Spearman's correlation coefficient, rho), responsiveness, and agreement between utility measures (ICC and Bland-Altman method).
\end{abstract}

Results: A total of 1,105 idiopathic OAB patients were included. Mean age (range) was 60.4 years (18-90), $87.8 \%$ $(n=970)$ were female. DIF was identified in 3 items, none of which are contained in the IUI. ICC (CI95 \%) was 0.944 $(0.936-0.950)$. Statistically significant differences $(p<0.001)$ were found in IUI scores for patients improving according to the Treatment Benefit Scale (TBS). Moderate to strong correlations (rho $>|0.6|$ ) were found in the expected direction with daily incontinence, urgency episodes and disease-specific domains of King's Health Questionnaire (KHQ). Low to moderate correlations (rho:<|0.6|) were found with Short Form version 2 (SF-12v2) summary components. A large effect size was found for patients reporting improvement (0.98-1.21) or great improvement (1.87-2.56) in the TBS, as well as in patients responding to treatment (1.19-2.40). Across utility measures, directional trends were consistent with $\mathrm{OAB}$ symptom profile, however, a lack of agreement in absolute values was observed.

Conclusions: The IUI presents good psychometric properties for valuing the impact of UI-related problems in idiopathic OAB patients.

Trial registration: ClinicalTrials.gov: NCT00910845 and NCT00910520.

Keywords: Overactive bladder, Urinary incontinence, Utility assessment, Health-related quality of life, I-QOL

\footnotetext{
* Correspondence: nacho.castejon@la-ser.com

'LA-SER Outcomes, C/ Azcárraga 12 A 33010 Oviedo, Asturias, Spain

Full list of author information is available at the end of the article
} 


\section{Background}

Overactive bladder $(\mathrm{OAB})$ is defined by the International Continence Society as "urgency, with or without urge incontinence, usually with frequency and nocturia" [1]. Prevalence rates of OAB range from 12 to $20 \%$ in men and women and increase with age in both populations [2-5]. Previous research has shown that OAB, especially when accompanied with urinary incontinence (UI) or urgency urinary incontinence (UUI), considerably impacts patients' health related quality of life (HRQoL) [6-9], affecting domains related to emotional well-being and social participation (e.g., avoidance and limiting behaviours) $[7,8]$, and also resulting in decreased work productivity $[7,10,11]$.

Preference-based values, or utilities, are commonly used in health economics to weight health states associated with different conditions. These outcomes are of importance for economic resources allocation because they allow for estimation of Quality-Adjusted Life-Years (QALYs) by multiplying life expectancy with the utility value associated with a given health state. The QALY is considered an appropriate measure of health benefit because it reflects both mortality and health-related quality of life (HRQoL) impacts associated with a health condition [12]. Among the available approaches to obtain utilities, the administration of currently existing generic preferencebased instruments such as the EuroQol-5D [EQ-5D]) [13-15] is commonly preferred by different health technology agencies in favor of promoting consistency and equity in decision-making and making this process more practical $[12,16-18]$. However, in cases where generic utility instruments may not capture clinically important changes, as has been shown among patients with UI related problems [19, 20], disease-specific community-based utility instruments may be considered more appropriate.

The Incontinence Utility Index (IUI) was recently created for measuring the health states related to urinary symptoms in neurogenic patients with $\mathrm{OAB}$ and UI symptoms [21]. This tool was derived from the previously validated I-QOL questionnaire and its neurogenic module $[22,23]$ in accordance with the latest methodological recommendations [24]. The I-QOL is a widely used instrument in clinical research to address patients' HRQoL associated with experiencing urinary problems $[8,22,25,26]$. Development of the IUI was comprised of two stages and has been described in detail previously [21].

The IUI was originally developed from a sample of patients with neurogenic detrusor overactivity (NDO) and UI related symptoms, hence new research is needed to support use of this instrument in other populations experiencing lower urinary tract symptoms. Consequently, the present study was conducted to test the measurement properties of the IUI among patients with idiopathic OAB. The performance of the abbreviated health state classification system underlying the IUI and the utility estimates resulting from its application were compared with the original I-QOL and two other utility measures collected from the same sample, respectively.

\section{Methods}

\section{Sample}

$\mathrm{OAB}$ cases included in the present analysis were adult patients with idiopathic $\mathrm{OAB}$ and UI, participating in two multicenter, international, Phase 3 , randomized, double-blind, placebo-controlled studies to evaluate the safety and efficacy of a single treatment of BOTOX ${ }^{\circ}$ (onabotulinumtoxinA, Allergan Inc.). Eligible patients had idiopathic OAB with UI, were considered to be inadequately managed by anticholinergic therapy (insufficient efficacy or intolerable side effects), and experienced $\geq 3$ episodes of urinary urgency incontinence (UUI) in a 3-day patient bladder diary, an average of $\geq 8$ micturitions per day and a post-void residual urine volume $\leq 100 \mathrm{ml}$. A full description of their characteristics and study design can be found elsewhere [27, 28].

In order to test the differential item functioning by sample etiology, the sample originally used for item selection of the IUI is also included in this study. This sample was comprised of patients with UI due to NDO as a result of spinal cord injury or multiple sclerosis, recruited during two multicenter, double-blind, randomized, placebocontrolled, parallel-group studies $[29,30]$.

\section{Ethics, consent and permissions}

Before entering in the aforementioned clinical trials all patients had to provide their written informed consent and all the studies were conducted in full compliance with the ethical principles regarding human experimentation of the Declaration of Helsinki. The New York University School of Medicine IRB, with Federal Wide Assurance number 00004952 reviewed the studies.

\section{Clinical variables and outcomes measures}

Basic clinical and socio-demographic data were collected to describe the sample of the study. The following patient reported outcomes (PROs) were administered to patients in these studies:

- Treatment Benefit Scale (TBS) [31]: a single-item measure that evaluates patients' perception of benefit following treatment. Responses are defined as $1=$ greatly improved; $2=$ improved; $3=$ not changed; $4=$ worsened. The TBS has demonstrated validity and responsiveness in previous clinical trials with antimuscarinic treatments in patients with $\mathrm{OAB}$ [31]. 
- Short Form-12 Health Survey version 2 (SF-12) [14, 32, 33]: A generic HRQoL questionnaire that includes 12 items from the SF-36 Health Survey [34] and has two component summary scores (physical-PCS- and mental-MCS-). Scores from patients' responses are normalized to a distribution of $50 \pm 10$ (using U.S. general population norms), and a higher score indicates better HRQoL. It has demonstrated adequate psychometric properties to estimate the health burden of chronic conditions in general population surveys [33, 35]. A preference-based weighted index can be estimated from this instrument (SF-6D) following the models proposed by Brazier et al. [14]. The range of the observed utility values varies between 0.30 (worst health state) to 1.0 (best health state) [36].

- King's Health Questionnaire (KHQ) [37, 38]: This selfadministered disease-specific HRQoL questionnaire for UI has 21 items (4-point Likert scale) covering 8 domains: urinary symptom severity, role limitations, physical functioning, social functioning, emotional problems, personal relationships, sleep disturbance, and general health. The range of scores for each domain is between 0 and 100, with higher scores indicating greater impact on patients' HRQoL (worse perceived health status). A condition-specific preference-based index has been developed from this instrument through reducing the number of dimensions (from 8 to 5), and valuing the resulting health state classification framework using direct elicitation (standard gamble) in a representative sample of patients with UI attending UK hospital outpatients clinics. Different models were tested to better adjust the predicting valuations for all the possible health states defined by this utility measure $(n=1024)$ [38]. Mean utility values obtained with the KHQ range from 0.77 to 0.98 .

- Incontinence Quality of Life Questionnaire (I-QOL) [22, 23, 26]: This self-administered questionnaire comprises 22 items (5 Likert point) distributed into three dimensions. These principal domains are: avoidance and limiting behavior (items 1-4, 10, 11, 13 and 20), psychosocial impact (items 5-7, 9, 15-17, 21 and 22), and social embarrassment (items $8,12,14,18$ and 19). A total scale score is calculated by summing the scores of all items included in an scale and transforming them into a 0-100 scale (higher scores reflect better HRQoL) [22].

The abbreviated health states classification system comprises 5 items or attributes (Fig. 1). Utility scores can be derived from this instrument by applying the IUI algorithm: IUI utility score $=1.051\left(\mathrm{~b} 1{ }^{*} \mathrm{~b} 2{ }^{*} \mathrm{~b} 3{ }^{*}\right.$ b4 * b5) - 0.051, where b is the estimated weight attached to the 3 different levels of each of the 5 attributes. The IUI has a utility score ranging from 0.036 (worst health state) to 1 (perfect health) [21].

\section{Statistical approach}

A number of analyses were undertaken to assess the performance of the IUI in this sample of OAB patients:

Rasch analysis was used to check for the presence of differential item functioning (DIF, or measurement bias) of the I-QOL between patients with OAB and NDO patients from which the IUI was originally developed. Items were calibrated and subjects were scored using the Partial Credit Model [39]. DIF was tested by segmenting the sample by etiology [40]. The presence of DIF suggests that patients with the same disease severity tend to respond differently to an item depending on their disease etiology. DIF was considered significant with $\mathrm{p}<0.001$, and relevant if the difference between groups exceeded 0.5 logits.

In addition, further tests were applied to assess the psychometric performance of the abbreviated health state classification defined in the IUI and the associated utility scores in this sample of $O A B$ patients.

\section{Concordance between I-QOL versions}

The agreement between the original I-QOL and its abbreviated health state classification system in OAB patients was analyzed by applying the intraclass correlation coefficient (ICC) at baseline and at week 12. Two-way mixed effects models (people effects are random and measures effects are fixed) was applied with an absolute agreement type with average measures (reliability of the mean of the instruments). It is generally recommended that ICC be at least 0.7 [41], with higher values indicating better concordance.

\section{Validity}

Criterion validity was assessed by studying the differences in both the I-QOL and the abbreviated form according to TBS scores at Week 12. Kruskal-Wallis (with Bonferroni's correction for multiple comparisons) tests were conducted for this purpose. Statistically significant differences between TBS levels $(\mathrm{p}<0.05)$ were expected in the scores of the I-QOL and its derived measures. Next, the relationship between the I-QOL, its abbreviated health state classification system, and the IUI with other PRO and clinical variables were evaluated. Spearman rank correlations coefficients (rho) were calculated between these instruments and the following clinical variables: age, volume voided per micturition $(\mathrm{mL} / 24 \mathrm{~h})$, daily incontinence episodes, daily urgency episodes, daily micturition episodes, daily incontinence urgency episodes, number of daily nocturia episodes and weekly incontinence episodes. Finally, convergent validity of the I-QOL, the abbreviated 


\begin{tabular}{|c|c|c|c|}
\hline Attributes & Levels of response & $\begin{array}{c}\text { *Scores } \\
\text { abbreviated } \\
\text { I-QOL } \\
\text { form }\end{array}$ & $\begin{array}{l}\text { Weights } \\
\text { IUI }\end{array}$ \\
\hline \multirow{3}{*}{$\begin{array}{l}\text { I-QOL } \\
\text { Item5: } \\
\text { Depressio } \\
\text { n }\end{array}$} & $\begin{array}{l}\text { I feel not at all depressed because of my urinary } \\
\text { problems or incontinence }\end{array}$ & 5 & 1.000 \\
\hline & $\begin{array}{l}\text { I feel somewhat depressed because of my urinary } \\
\text { problems or incontinence }\end{array}$ & 3 & 0.821 \\
\hline & $\begin{array}{l}\text { I feel extremely depressed because of my urinary } \\
\text { problems or incontinence }\end{array}$ & 1 & 0.633 \\
\hline \multirow{3}{*}{$\begin{array}{l}\text { I-QOL } \\
\text { Item8: } \\
\text { Urine } \\
\text { Smell }\end{array}$} & $\begin{array}{l}\text { I do not worry at all about other people smelling urine } \\
\text { on me }\end{array}$ & 5 & 1.000 \\
\hline & $\begin{array}{l}\text { I worry somewhat about other people smelling urine on } \\
\text { me }\end{array}$ & 3 & 0.750 \\
\hline & $\begin{array}{l}\text { I worry a very great deal about other people smelling } \\
\text { urine on me }\end{array}$ & 1 & 0.524 \\
\hline \multirow{3}{*}{$\begin{array}{l}\text { I-QOL } \\
\text { Item13: } \\
\text { Sleep }\end{array}$} & $\begin{array}{l}\text { I have no difficulty getting a good night's sleep because } \\
\text { of my urinary problems or incontinence }\end{array}$ & 5 & 1.000 \\
\hline & $\begin{array}{l}\text { I have some difficulty getting a good night's sleep } \\
\text { because of my urinary problems or incontinence }\end{array}$ & 3 & 0.832 \\
\hline & $\begin{array}{l}\text { I have extreme difficulty getting a good night's sleep } \\
\text { because of my urinary problems or incontinence }\end{array}$ & 1 & 0.644 \\
\hline \multirow{3}{*}{$\begin{array}{l}\text { I-QOL } \\
\text { Item19: } \\
\text { Bladder } \\
\text { Control }\end{array}$} & I feel I have control over my bladder & 5 & 1.000 \\
\hline & I feel I have some control over my bladder & 3 & 0.791 \\
\hline & I feel I have no control over my bladder & 1 & 0.539 \\
\hline \multirow{3}{*}{$\begin{array}{l}\text { I-QOL } \\
\text { Item20: } \\
\text { Drinks }\end{array}$} & $\begin{array}{l}\text { I have to be not at all careful about what or how much I } \\
\text { drink because of my urinary problems or incontinence }\end{array}$ & 5 & 1.000 \\
\hline & $\begin{array}{l}\text { I have to be somewhat careful about what or how much } \\
\text { I drink because of my urinary problems or incontinence }\end{array}$ & 3 & 0.883 \\
\hline & $\begin{array}{l}\text { I have to be extremely careful about what or how much } \\
\text { I drink because of my urinary problems or incontinence }\end{array}$ & 1 & 0.721 \\
\hline \multicolumn{4}{|c|}{$\begin{array}{l}\text { * A summary scale score for the abbreviated form of the I-QOL can be transformed into a } \\
0 \text { (worst health status) }-100 \text { (best health status) scale with the following algorithm: } \\
\text { Total score }=\text { (the sum of the } 5 \text { items - lowest possible score / possible raw score range) } \\
* 100 \text {. }\end{array}$} \\
\hline
\end{tabular}

Fig. 1 Incontinence Utility Index (IUI) attributes and levels

health state classification system, and the IUI were studied by testing its association (rho) with respect to the KHQ global score and domains, the SF-12 (Physical and Mental Component Summaries) and the utility scores derived from the KHQ and the SF-12 using Spearman rank correlation. A moderate to strong association (rho $\geq 0.5$ ) was expected between the I-QOL and other disease-specific variables (e.g., disease-specific domains of the KHQ or the number of incontinence episodes), while the association between the I-QOL and variables less directly related to $\mathrm{OAB}$ (e.g., generic domains of the KHQ and the SF-12 summary components) was hypothesized to be lower (rho between 0.3 and 0.49 ).

\section{Responsiveness}

The ability of the abbreviated form of the I-QOL and the IUI to capture clinically relevant changes in OAB patients were analyzed according to the level of response to treatment and TBS scale. To this end, differences in scores between baseline and Week 12 visits were calculated via Wilcoxon tests, standardized response means (SRMs) and effect size statistics. Patients were classified as respondents according to clinical criteria depending on the average percentage reduction in daily UI episodes from baseline: $50 \%, 75 \%$ or $100 \%$ of reduction in daily episodes according to the 3-day bladder diary at week 12 [42]. SRMs were calculated as the mean change score (score at week12 minus score at baseline) divided by the standard deviation of change score. Effect size statistics were calculated as the mean change score divided by the standard deviation at baseline [8]. It was hypothesized that higher effect sizes were to be found between patients with a higher response or perceived benefit at week 12. Conventional benchmarks to interpret effect sizes are as follows: an effect size of $0.2-0.49$ is considered small, 0.5-0.79 medium and over 0.8, large [43]. 


\section{Agreement between utility measures}

Bland-Altman diagrams for agreement and the ICC statistic (with a two-way mixed effects model and checking an absolute agreement type with average measures) at baseline and Week 12 were used to study to what extent the utility values from the IUI and those obtained from the SF-12 [14] and the KHQ [38] could be interchangeable. The limits of agreement in the Bland-Altman figures were defined at a distance from the mean of 1.96 times the standard deviation of the differences. Acceptable limits of concordance of \pm 0.1 points from 0 (maximum concordance in mean values) are also displayed to represent relevant discrepancies in common utility scales $[44,45]$.

The statistical packages SPSS 21.0 and Winsteps 3.75 were used to conduct the analyses above.

\section{Results}

A total of 1,105 idiopathic OAB patients with UI symptoms were included. A majority of them were female (87.8 \%) and Caucasian (90.9\%). Mean age (range) was 60.4 years (18 to 90 ). Patients had a median duration of $\mathrm{OAB}$ of 5 years and reported a mean (SD) of 5.44 (3.62) daily UI episodes, 4.90 (3.43) daily urgency urinary incontinence episodes, 11.74 (3.78) daily micturitions, 8.57 (4.40) daily urgency episodes, and 2.11 (1.42) nocturia episodes per day at study baseline. A summary of select patient demographic and clinical characteristics can be found in Table 1.

Rasch analysis showed three items presented statistically significant differential item functioning with a relevant effect with respect to etiology of urinary symptoms (neurogenic vs. idiopathic). Details can be found on Table 2. Items exhibiting DIF included content related to trips to the toilet, aging and sexual activity. However, as none of the affected items were included in development of attributes and subsequent preference elicitation for the IUI no further action was deemed necessary.

A high level of agreement was found between the abbreviated form of the I-QOL and the original version at both baseline and week 12: ICC $=0.900$ (CI $95 \%$ : 0.886-0.912) and 0.944 (CI $95 \%$ : 0.936-0.950). A statistically significant difference was seen for I-QOL scores, the abbreviated health state descriptive system, and the IUI scores across perceived benefit levels after 12 weeks of treatment (TBS scale, Kruskal-Wallis Test $\mathrm{p}<0.001$, Table 3). Pairwise comparisons with Bonferroni correction were also statistically significant, with exception of scores between patients who indicated that their health condition had either not changed or worsened.

Table 4 shows the relationship between I-QOL versions, clinical variables and other HRQoL instruments. As hypothesized, correlation coefficients reflected a negative and moderate to strong association between I-QOL
Table 1 Select baseline demographic, clinical, and patientreported characteristics: OAB pooled study population

\begin{tabular}{|c|c|c|c|}
\hline \multirow[t]{2}{*}{ Variables } & \multicolumn{3}{|c|}{ Baseline } \\
\hline & $\mathrm{n}$ & Mean & SD \\
\hline Age & 1105 & 60.36 & 13.90 \\
\hline Female $(n, \%)$ & 970 & $87.8 \%$ & \\
\hline Caucasian (n, \%) & 1004 & $90.90 \%$ & \\
\hline Duration of $O A B$ (years) & 1104 & 6.09 & 7.07 \\
\hline Volume Voided Per Micturition (mL/24 h) & 1021 & 153.60 & 62.57 \\
\hline Daily Micturition Episodes & 1026 & 11.74 & 3.78 \\
\hline Daily Incontinence Episodes & 1026 & 5.44 & 3.62 \\
\hline Daily Urgency Episodes & 1026 & 8.57 & 4.40 \\
\hline Daily Urinary Urgency Incontinence Episodes & 1026 & 4.90 & 3.43 \\
\hline Daily Nocturia Episodes & 1026 & 2.11 & 1.42 \\
\hline I-QOL Total Summary Score & 1101 & 34.42 & 18.77 \\
\hline I-QOL Avoidance and Limiting Behavior Score & 1103 & 31,43 & 16.99 \\
\hline I-QOL Psychosocial Impacts Score & 1103 & 42.62 & 24.29 \\
\hline I-QOL Social Embarrassment Score & 1103 & 24.69 & 20.93 \\
\hline I-QOL Abbreviated Form & 1100 & 36.12 & 18.31 \\
\hline IUI Scores & 1100 & 0.22 & 0.14 \\
\hline \multicolumn{4}{|l|}{ KHQ Domains } \\
\hline General Health Perceptions Score & 1099 & 31.76 & 23.82 \\
\hline Incontinence Impact Score & 1099 & 83.35 & 23.91 \\
\hline Role Limitations Score & 1099 & 63.32 & 29.04 \\
\hline Social Limitations Score & 1099 & 43.59 & 30.97 \\
\hline Personal Relationships Score & 834 & 37.03 & 35.70 \\
\hline Emotions Score & 1099 & 55.67 & 30.30 \\
\hline Sleep/Energy Score & 1099 & 65.00 & 26.77 \\
\hline Severity Measures Score & 1099 & 65.12 & 22.97 \\
\hline King's Health Questionnaire (KHQ) Utility Score & 1099 & 0.93 & 0.02 \\
\hline \multicolumn{4}{|l|}{ SF-12v2 Outcomes } \\
\hline Physical Component Summary Score (PCS) & 1096 & 43.22 & 10.03 \\
\hline Mental Component Summary Score (MCS) & 1096 & 43.19 & 11.98 \\
\hline SF-12v2 Health Survey Utility Score (SF-6D) & 1096 & 0.66 & 0.13 \\
\hline
\end{tabular}

versions and those clinical variables related to UI problems (rho > $|0.6|$ ): daily incontinence episodes and urgency episodes, indicating that greater frequency of UI related problems was associated with lower I-QOL scores. Age was not significantly related to I-QOL scores. Furthermore, the scores obtained from the I-QOL and its derived instruments were negative and moderately to strongly associated with disease-specific HRQoL domains of the KHQ (rho $>|0.6-0.8|$ ), with the Severity Measures and Emotions domains having the strongest relationship to I-QOL measures. As expected, the association with the summary components of the SF-12, a measure of general HRQoL, were positive but low to moderate: low 
Table 2 Rasch analysis: differential item functioning by etiology (NDO vs. OAB)

\begin{tabular}{|c|c|c|c|c|c|c|c|c|}
\hline Item & & NDO measure & NDO S.E. & OAB measure & OAB S.E. & DIF contrast & Welch $\mathrm{t}$ & $p$-value \\
\hline 1 & I worry about getting to toilet in time & 0.30 & 0.04 & 0.65 & 0.04 & -0.35 & -6.03 & $<0.001$ \\
\hline 2 & I worry about coughing and sneezing & -1.17 & 0.04 & -0.85 & 0.03 & -0.31 & -6.50 & $<0.001$ \\
\hline 3 & I'm careful when standing up & -0.95 & 0.04 & -0.71 & 0.03 & -0.24 & -5.07 & $<0.001$ \\
\hline 4 & I worry about where toilets are located & 0.36 & 0.04 & 0.61 & 0.04 & -0.24 & -4.33 & $<0.001$ \\
\hline 5 & I feel depressed due to urinary problem ${ }^{a}$ & -0.35 & 0.04 & -0.26 & 0.03 & -0.08 & -1.65 & 0.099 \\
\hline 6 & I don't feel free to leave my home & -0.21 & 0.04 & -0.35 & 0.03 & 0.14 & 2.94 & 0.003 \\
\hline 7 & I'm prevented from doing what I want & 0.24 & 0.04 & 0.10 & 0.03 & 0.14 & 2.62 & 0.009 \\
\hline 8 & I worry about a urine smell on me $\mathrm{e}^{\mathrm{a}}$ & -0.40 & 0.04 & -0.33 & 0.03 & -0.06 & -1.33 & 0.184 \\
\hline 9 & Urine problems are always on my mind & 0.50 & 0.05 & 0.50 & 0.04 & 0.00 & 0.00 & 1.000 \\
\hline 10 & I make frequent trips to the toilet & 0.27 & 0.04 & 0.96 & 0.04 & -0.69 & -11.3 & $<0.001$ \\
\hline 11 & Important to plan details in advance & 0.30 & 0.05 & -0.09 & 0.03 & 0.39 & 6.93 & $<0.001$ \\
\hline 12 & I worry urine problems will worsen w/age & 0.27 & 0.04 & 0.86 & 0.04 & -0.59 & -10.3 & $<0.001$ \\
\hline 13 & I can't get a good night of sleep ${ }^{a}$ & -0.13 & 0.04 & 0.03 & 0.03 & -0.17 & -3.39 & 0.001 \\
\hline 14 & I worry about being embarrassed & 0.41 & 0.04 & 0.39 & 0.03 & 0.02 & 0.42 & 0.674 \\
\hline 15 & I feel like I'm not a healthy person & -0.34 & 0.04 & -0.56 & 0.03 & 0.22 & 4.45 & $<0.001$ \\
\hline 16 & I feel helpless due to urinary problems & -0.52 & 0.04 & -0.52 & 0.03 & 0.00 & 0.00 & 1.000 \\
\hline 17 & I get less enjoyment out of life & -0.16 & 0.04 & -0.26 & 0.03 & 0.10 & 2.00 & 0.045 \\
\hline 18 & I worry about wetting myself & 0.83 & 0.05 & 0.81 & 0.04 & 0.02 & 0.34 & 0.735 \\
\hline 19 & I feel I can't control my bladder ${ }^{a}$ & 1.12 & 0.05 & 0.74 & 0.04 & 0.37 & 5.68 & $<0.001$ \\
\hline 20 & I watch what and how much I drink ${ }^{a}$ & 0.51 & 0.05 & 0.36 & 0.03 & 0.15 & 2.61 & 0.009 \\
\hline 21 & My choice of clothing is limited & -0.53 & 0.04 & -0.68 & 0.03 & 0.15 & 3.13 & 0.002 \\
\hline 22 & I worry about having sex & -0.55 & 0.03 & -1.14 & 0.03 & 0.59 & 13.13 & $<0.001$ \\
\hline
\end{tabular}

DIF: differential item functioning altems which constitute the descriptive system of the IUI. DIF contrast in bold indicate items which exhibited differential item functioning

Table 3 Differences in the I-QOL and IUI scores according to the Treatment Benefit Scale (TBS) at week 12

\begin{tabular}{|c|c|c|c|c|c|c|c|}
\hline & \multirow[t]{2}{*}{ Treatment benefit scale } & \multirow[t]{2}{*}{ Number } & \multirow[t]{2}{*}{ Mean } & \multirow[t]{2}{*}{ SD } & \multicolumn{2}{|c|}{$95 \%$ Cl for mean } & \multirow[t]{2}{*}{ p-value } \\
\hline & & & & & Lower & Upper & \\
\hline \multirow[t]{4}{*}{ I-QOL scale score } & Greatly improve & 187 & 77.49 & 20.70 & 74.51 & 80.48 & \multirow[t]{4}{*}{$<0.001$} \\
\hline & Improved & 274 & 57.36 & 22.69 & 54.67 & 60.06 & \\
\hline & Not changed $^{\mathrm{a}}$ & 464 & 37.21 & 20.42 & 35.35 & 39.08 & \\
\hline & Worsened $^{\mathrm{a}}$ & 109 & 31.46 & 19.95 & 27.67 & 35.25 & \\
\hline \multirow{4}{*}{$\begin{array}{l}\text { Scale score of the abbreviated } \\
\text { form of the I-QOL }\end{array}$} & Greatly improve & 187 & 72.19 & 20.77 & 69.20 & 75.19 & \multirow[t]{4}{*}{$<0.001$} \\
\hline & Improved & 274 & 54.71 & 19.97 & 52.33 & 57.08 & \\
\hline & Not changed ${ }^{a}$ & 464 & 37.95 & 19.23 & 36.20 & 39.71 & \\
\hline & Worsened $^{\mathrm{a}}$ & 109 & 33.58 & 18.64 & 30.04 & 37.12 & \\
\hline \multirow[t]{4}{*}{ IUI scores } & Greatly improve & 187 & 0.60 & 0.27 & 0.56 & 0.64 & \multirow[t]{4}{*}{$<0.001$} \\
\hline & Improved & 274 & 0.39 & 0.20 & 0.37 & 0.42 & \\
\hline & Not changed ${ }^{a}$ & 464 & 0.24 & 0.16 & 0.23 & 0.25 & \\
\hline & Worsened $^{\mathrm{a}}$ & 109 & 0.21 & 0.14 & 0.18 & 0.23 & \\
\hline
\end{tabular}

${ }^{a}$ After applying Bonferroni's correction, all comparisons established by TBS levels were significant with the exception of that between not changed vs worsened levels 
Table 4 Responsiveness of I-QOL and IUI across clinical criteria at week 12

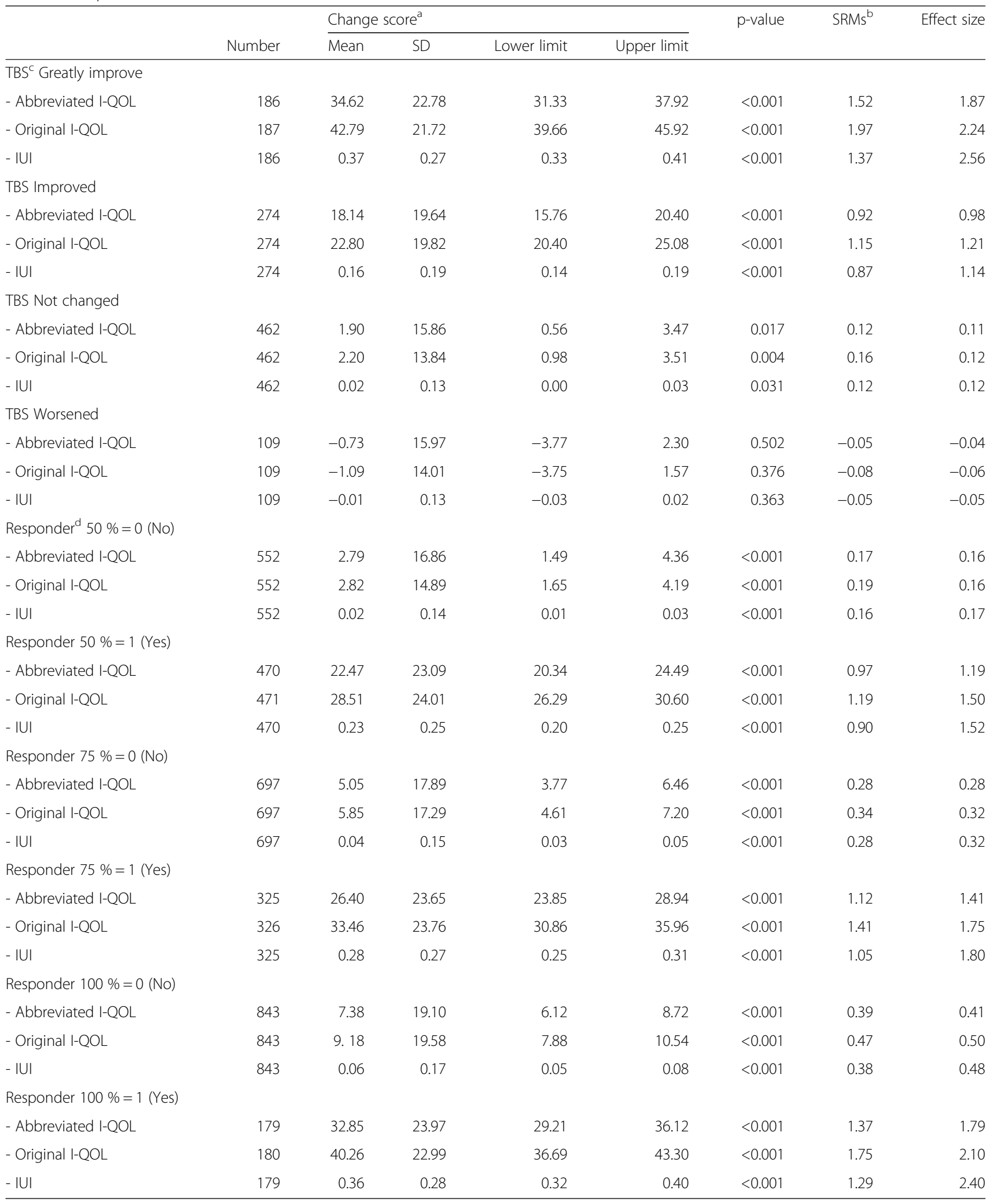

${ }^{\mathrm{a}}$ Change score $=$ scores at week 12 minus scores at baseline

bSRM: Standardized response means

'TBS: Treatment Benefit Scale

${ }^{\mathrm{d}}$ Responder: calculated from the average percentage of reduction in daily UI episodes from baseline 
Iwith respect to the physical component summary score (rho range: $0.25-0.31$ ) and moderate relative to the mental component summary score (rho range $=0.47-0.52$ ).

The responsiveness of I-QOL versions was evaluated using SRMs and effect sizes by week 12 TBS levels and responder definitions (Table 4). Scores from patients who reported an improvement in symptoms corresponded with a large effect size in all the I-QOL derived instruments (range: 0.98-1.21), with scores from patients reporting symptoms had "Greatly improved" showing higher effect sizes (range: 1.87-2.56). Furthermore, effect sizes were low between those patients reporting no changes or being worse at week 12 from baseline (range: 0.04-0.12). The same trend was observed in the case of the responder classification implemented according to the percentage of UI episodes reduction: the higher the reduction in the frequency of UI related symptoms, the higher the effect sizes. For instance, between patients reporting a benefit of $50 \%$ of reduction in UI episodes, effect sizes ranged from 1.19 to 1.52 while among those with $100 \%$ reduction the range was $1.79-2.40$.
With regards to the concordance between utility values, although the associations between the IUI and the utilities scores from the KHQ and the SF-12 (SF-6D) were significant, positive and moderate to strong (0.761 and 0.469, respectively, $\mathrm{p}<0.001$ ) (Table 5), Bland-Altman methods highlighted poor agreement between these measures meaning that large differences in utility values were seen in the scatterplots (Figs. 2, 3 and 4). Mean differences (SD) between utility values from IUI and both KHQ and SF-6D were: $-0.70(0.13)$ and $-0.44(0.15)$ at baseline and $-0.60(0.22)$ and $-0.34(0.22)$ at week 12 , respectively. The agreement between the utility scores obtained from the KHQ and the SF-6D was also low: mean differences of values $(\mathrm{SD})$ was $0.27(0.12)$ at baseline and $0.26(0.12)$ at week 12, far exceeding acceptable concordance thresholds. This low agreement was confirmed by ICC results: all the comparisons (at baseline and at week 12) were under the accepted threshold (0.7) and ranged from 0.014 to 0.2 .

\section{Discussion}

This study presents the measurement properties of the IUI in a sample of idiopathic OAB patients with UI

Table 5 Association between I-QOL and IUI scores with clinical variables and measures at week 12

\begin{tabular}{|c|c|c|c|}
\hline & I-QOL Scale score & Abbreviated form of the I-QOL Scale score & IUI Scores \\
\hline Age in Years $(n=1038)$ & $-0.038^{*}$ & $-0.026^{*}$ & $-0.032^{*}$ \\
\hline Volume Voided Per Micturition $(n=1021)$ & $0.227^{* *}$ & $0.236^{* *}$ & $0.233^{* *}$ \\
\hline Daily Incontinence Episodes $(n=1026)$ & $-0.627^{* *}$ & $-0.579^{* *}$ & $-0.594^{* *}$ \\
\hline Daily Micturition Episodes $(n=1026)$ & $-0.375^{* *}$ & $-0.359^{* *}$ & $-0.347^{* *}$ \\
\hline Daily Urgency Episodes ( $n=1026)$ & $-0.537^{* *}$ & $-0.515^{* *}$ & $-0.510^{* *}$ \\
\hline Daily Incontinence Urgency Episodes ( $n=1026)$ & $-0.638^{* *}$ & $-0.589^{* *}$ & $-0.603^{* *}$ \\
\hline Daily Nocturia Episodes $(n=1026)$ & $-0.315^{* *}$ & $-0.333^{* *}$ & $-0.300^{* *}$ \\
\hline Weekly Incontinence Episodes $(n=1025)$ & $-0.626^{* *}$ & $-0.579^{* *}$ & $-0.594^{* *}$ \\
\hline I-QOL: Avoidance and Limiting Behavior Score $(n=1038)$ & $0.941^{* *}$ & $0.853^{* *}$ & $0.842^{* *}$ \\
\hline I-QOL: Psychosocial Impacts Score $(n=1038)$ & $0.964^{* *}$ & $0.846^{* *}$ & $0.841^{* *}$ \\
\hline I-QOL: Social Embarrassment Score $(n=1038)$ & $0.930^{* *}$ & $0.873^{* *}$ & $0.891^{* *}$ \\
\hline KHQ Utility Score $(n=1038)$ & $0.827^{* *}$ & $0.775^{* *}$ & $0.761^{* *}$ \\
\hline General Health Perceptions Score $(n=1036)$ & $-0.228^{* *}$ & $-0.195^{* *}$ & $-0.193^{* *}$ \\
\hline Physical functioning ( $n=1036)$ & $-0.775^{* *}$ & $-0.701^{* *}$ & $-0.698^{* *}$ \\
\hline Role Limitations Score $(n=1038)$ & $-0.783^{* *}$ & $-0.696^{* *}$ & $-0.693^{* *}$ \\
\hline Social Limitations Score $(n=1038)$ & $-0.755^{* *}$ & $-0.668^{* *}$ & $-0.660^{* *}$ \\
\hline Personal Relationships Score $(n=761)$ & $-0.587^{* *}$ & $-0.517^{* *}$ & $-0.510^{* *}$ \\
\hline Emotions Score $(n=1038)$ & $-0.807^{* *}$ & $-0.737^{* *}$ & $-0.728^{* *}$ \\
\hline Sleep/Energy Score $(n=1038)$ & $-0.617^{* *}$ & $-0.628^{* *}$ & $-0.605^{* *}$ \\
\hline Urinary symptoms severity score $(n=1038)$ & $-0.805^{* *}$ & $-0.763^{* *}$ & $-0.773^{* *}$ \\
\hline SF12 Utility Score (SF-6D) $(n=1034)$ & $0.528^{* *}$ & $0.476^{* *}$ & $0.469^{* *}$ \\
\hline Physical Component Summary Score $(n=1033)$ & $0.309^{* *}$ & $0.252^{* *}$ & $0.254^{* *}$ \\
\hline Mental Component Summary Score $(n=1033)$ & $0.517^{* *}$ & $0.477^{* *}$ & $0.468^{* *}$ \\
\hline
\end{tabular}




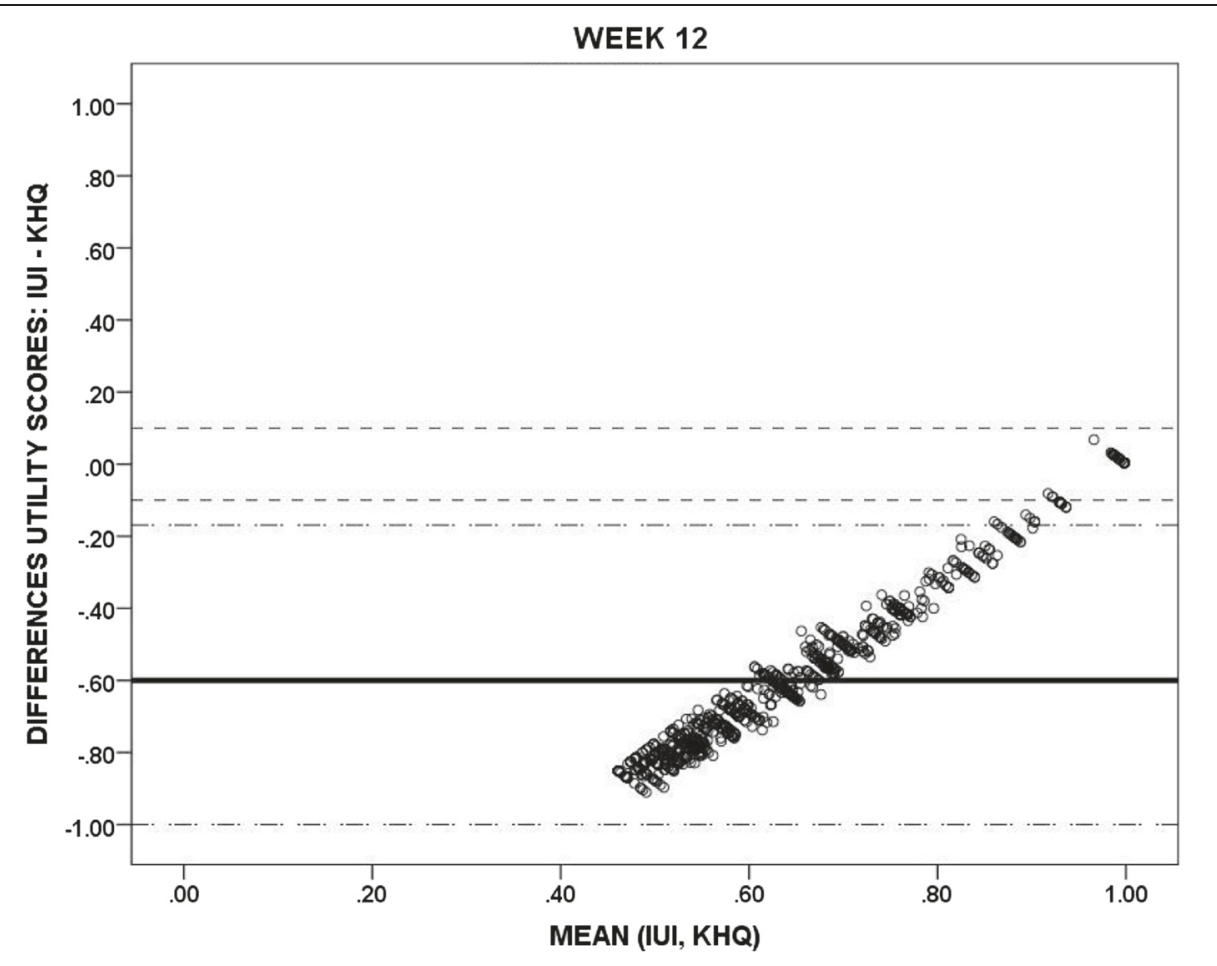

- - - - Limit of concordance set at $0 \pm 0.1$ in mean differences

.-.--. Limits of agreement: mean of differences $\pm 1.96 *$ standard deviation of differences.

Mean of differences

Fig. 2 Bland-Altman scatterplots: Concordance between Incontinence Utility Index (IUI) and King's Health Questionnaire (KHQ) utility scores

symptoms who had not been adequately managed with anticholinergic therapy. The health states covered with this societal preference-based utility measure were originally extracted from the I-QOL and its neurogenic module using a large sample of adult patients with NDO [21]. The abbreviated health state classification version of the I-QOL containing the descriptive system of the IUI did not include any items from the neurogenic module, hence it was appropriate to test its psychometric performance in idiopathic OAB patients with UI to provide evidence for use in health economic analyses comparing interventions of interest within this patient population. In a recent study, the I-QOL was shown to be a robust HRQoL instrument for measuring the impact of urinary problems in similar sample of idiopathic $\mathrm{OAB}$ patients [8] so it was reasonable to further explore the validity of the IUI in this target population.

Results of the Rasch analysis showed that none of the items included in the abbreviated health state classification system derived from the I-QOL exhibited DIF; that is, the IUI assigned comparable scores to analogous health states in NDO and idiopathic OAB patients. Interestingly, the three I-QOL items which did exhibit DIF pertained to aspects of life which would be expected to differ between these two patient populations (i.e., trips to the toilet, aging, and sexual activity). NDO patients may have limitations in "Trips to the toilet" and "Sexual activity" independently of UI, and their perspective on aging may be different compared to those with OAB. Responses on the items whose attributes were ultimately included in the IUI did not systematically differ across each sample.

A high level of absolute agreement between the original I-QOL and the descriptive system of the IUI was demonstrated by the ICC, which showed a very high proportion of variability that was attributed to variation between patients. This high degree of concordance indicates that IUI scores are a reliable indicator of urinary symptom impacts as measured by the I-QOL. In addition, both the abbreviated version of the I-QOL and the IUI captured significant differences relative to clinically meaningful variables such as the reduction in the number of UI episodes or the treatment benefit perceived by patients as evaluated by the TBS [31]. Clinically meaningful outcomes relevant to urinary symptoms (daily number of UI episodes, UUI frequency and nocturia) were moderately or strongly associated with IUI scores. The large 


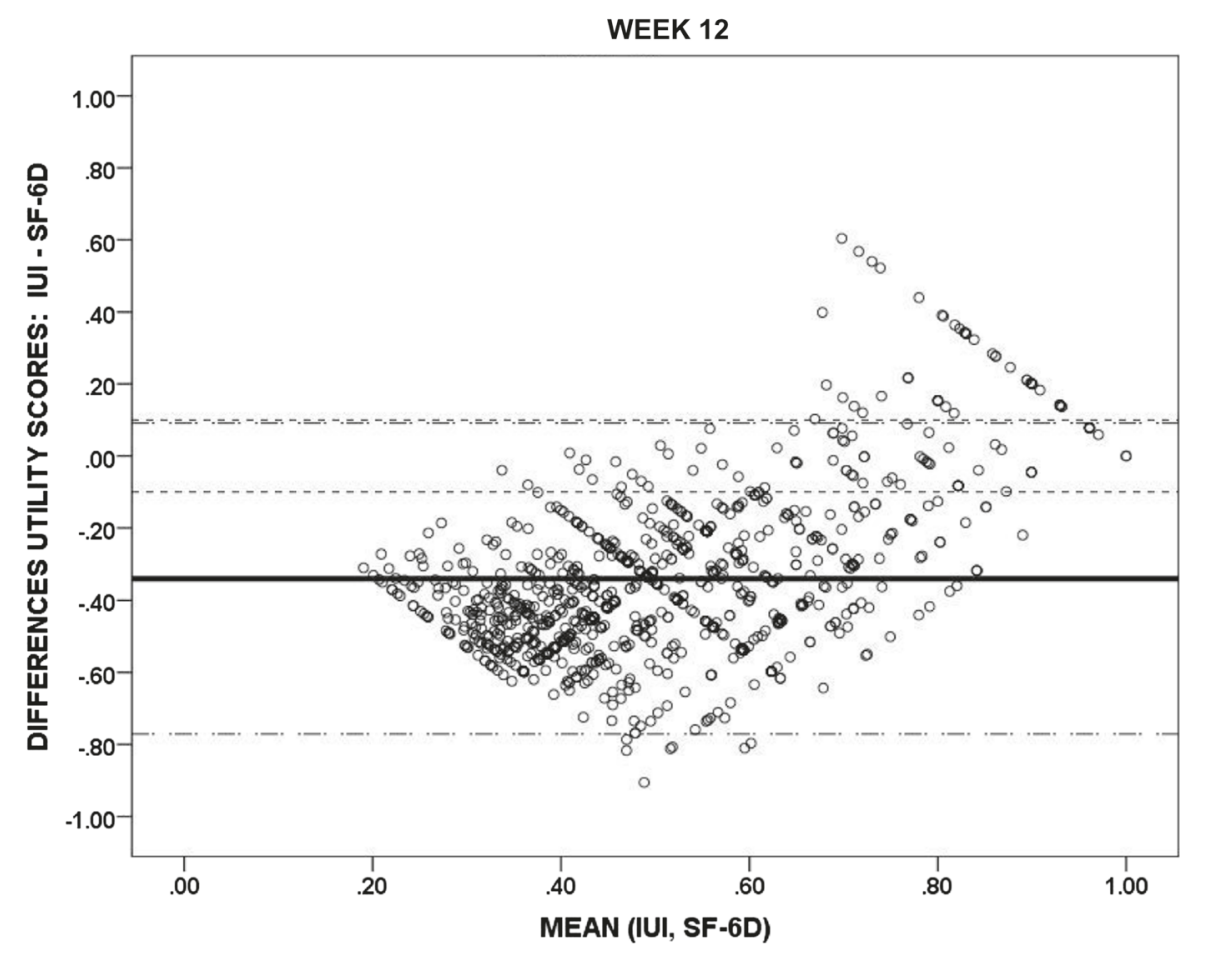

- - - - Limit of concordance set at $0 \pm 0.1$ in mean differences

.-.-.. Limits of agreement: mean of differences $\pm 1.96 *$ standard deviation of differences.

Mean of differences

Fig. 3 Bland-Altman scatterplots: Concordance between Incontinence Utility Index (IUI) and Short Form-12 Health Survey (SF-6D) utility scores

effect sizes $(\mathrm{d}>0.8)$ found between baseline and week 12 IUI scores among patients with a reduction in the frequency of UI symptoms are in accordance to previous publications using the I-QOL in OAB patients [8, 22, 46].

Although all utility measures demonstrated consistent trends (e.g., lower utility values were associated with poorer urinary symptom profile across all utility measures), a low level of agreement in absolute values was systematically found between the utility values estimated from each of the instruments. IUI utilities had the lowest absolute values relative to both the KHQ (conditionspecific) and the SF-6D (generic measure) at baseline and at week 12, while KHQ utility scores were the highest. Utility values were more reasonably similar only among patients whose health state was close to full or the most desirable health state. This lack of concordance and consistency across different utility measures to assess overall health status has been frequently described in the literature. For instance, this issue has been addressed when valuing the health states obtained in obese women with UI [47], or in musculoskeletal and cardiovascular diseases $[48,49]$ and in representative samples of the general population using generic instruments [50]. In the present study, these discrepancies between the IUI and the KHQ may be due to the different populations interviewed to derive the health state classification systems and to estimate the respective utility indexes. The health states described by the IUI were valued by the general population while those of the KHQ were assessed by UI patients attending hospital outpatient clinics [38]. In other pathologies, it has been highlighted that patients provided significantly different values to the health states related to the disease they experienced in comparison to general population [51, 52]. Given the existing heterogeneity, inclusion of more than one utility instrument should be considered in order to provide a more comprehensive evaluation of the possible range of the values attached to the health status of patients with certain health conditions [53].

A number of limitations in the present study should be addressed. First, although data for the analyses came from multiple global randomized phase III clinical trials, further research should be conducted to address regionspecific nuances with respect to self-reported health status. The samples utilized in this study are comprised of a specific subset of patients with urologic problems, 


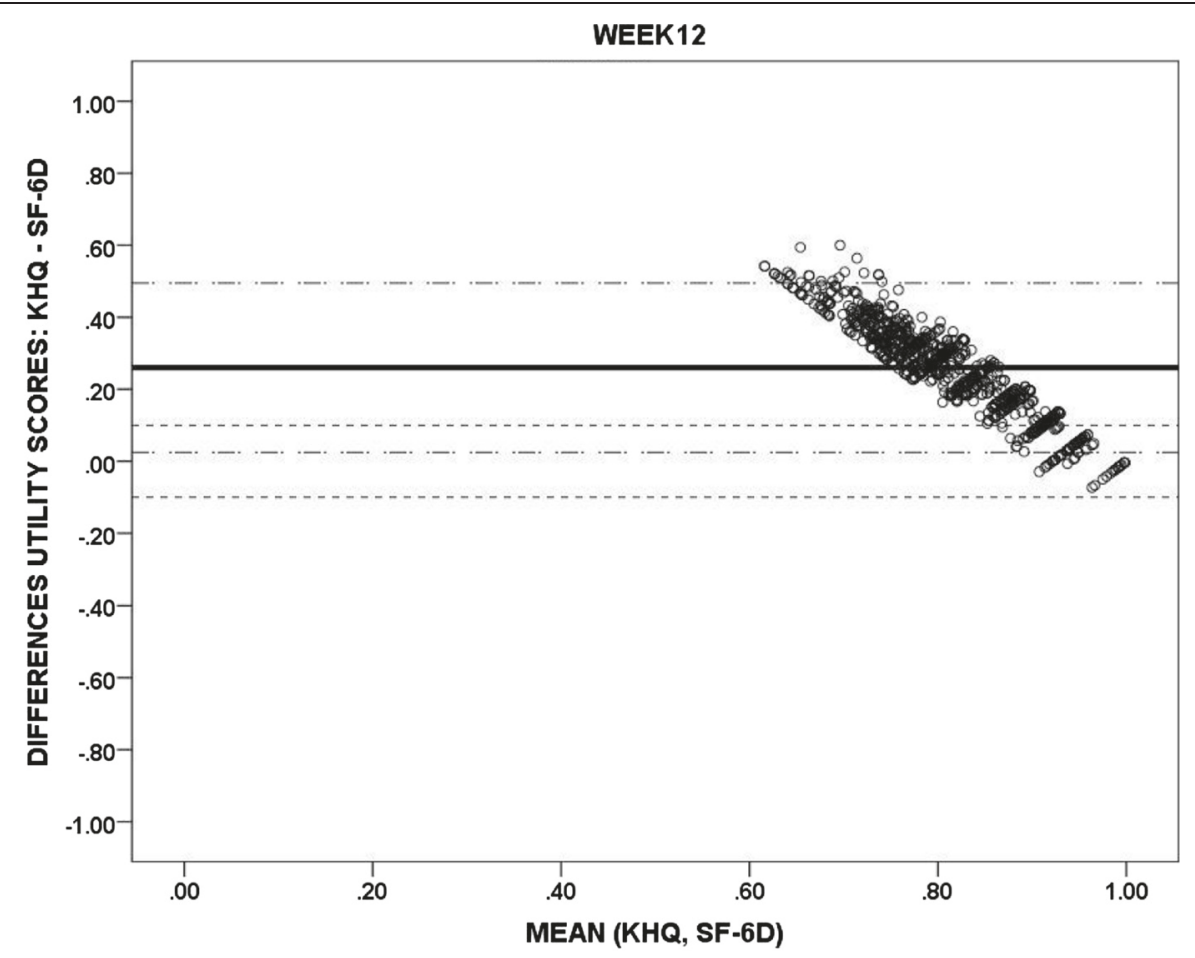

- - - - Limit of concordance set at $0 \pm 0.1$ in mean differences

.--.-. Limits of agreement: mean of differences $\pm 1.96 *$ standard deviation of differences.

Mean of differences

Fig. 4 Bland-Altman scatterplots: Concordance between King's Health Questionnaire (KHQ) and Short Form-12 Health Survey (SF-6D) utility scores

thus, inferences to other urology populations should be made with caution. Second, the majority of patients in the OAB studies $(87.5 \%)$ were female so additional testing is required before generalizing these conclusions to men with OAB. Despite these limitations, the present research demonstrates the IUI's ability to detect clinically important differences in $\mathrm{OAB}$ patients with UI and differentiate well across different levels of reported treatment benefit and symptom improvement. Thus the psychometric performance of the IUI was comparable to the original I-QOL.

In conclusion, the IUI is a valid instrument for the assessment of patients with urological symptoms related to idiopathic OAB. The utilities obtained from its application represent the societal value of the health states described and offers additional insight to researchers and HTAs when assessing the benefits of urological interventions for $\mathrm{OAB}$ and UI problems.

\section{Abbreviations}

BOTOX: OnabotulinumtoxinA; DIF: Differential item functioning; EQ5D: EuroQol-5 dimension; HRQOL: Health-related quality of life; ICC: Intraclass correlation coefficient; I-QOL: Incontinence quality of life questionnaire; IUI: Incontinence utility index; KHQ: King's health questionnaire;

NDO: Neurogenic detrusor overactivity; OAB: Overactive bladder; PRO: Patient reported outcome; QALY: Quality-Adjusted Life-Years; SF-12v2: Short form 12 health survey version 2; SF-6D: Short form-6 dimension; SRM: Standardized response means; TBS: Treatment benefit scale; UI: Urinary incontinence; UUI: Urgency urinary incontinence; UK: United Kingdom.

\section{Competing interests}

Financial support for this study was provided entirely by a contract with Allergan, Inc. The funding agreement ensured the authors' independence in designing the study, interpreting the data, writing, and publishing the report. KK and QN were employed by the sponsor during the writing of this manuscript:. At the time of submission, KK was not employed at Allergan, Inc. Furthermore, according to the purposes and scope of this work, authors hereby declare no other financial conflict of interests.

\section{Authors' contributions}

NC, JC designed and coordinated the study, conducted and reviewed the statistical analysis and drafted the manuscript. DLP supervised the design of the study, critically reviewed the statistical reports and the manuscript. KK participated in the design and coordination of this research, supervised the statistical analyses and collaborated drafting and critically reviewing the manuscript. QN supervised the statistical analyses and collaborated drafting and critically reviewing the manuscript. All authors revised and approved this final version of the manuscript.

\section{Acknowledgments}

The authors acknowledge Ms. Daisy Ng-Mak for her valuable feedback to the manuscript.

\section{Author details}

'LA-SER Outcomes, C/ Azcárraga 12 A 33010 Oviedo, Asturias, Spain.

${ }^{2}$ Allergan Inc., Irvine, CA, USA. ${ }^{3}$ Allergan Inc., Bridgewater, NJ, USA.

${ }^{4}$ Department of Health Services, University of Washington, Seattle, WA, USA.

Received: 26 January 2015 Accepted: 15 July 2015

Published online: 01 August 2015 


\section{References}

1. Abrams P, Andersson KE, Birder L, Brubaker L, Cardozo L, Chapple C, et al. Fourth International Consultation on Incontinence Recommendations of the International Scientific Committee: Evaluation and treatment of urinary incontinence, pelvic organ prolapse, and fecal incontinence. Neurourol Urodyn. 2010;29:213-40.

2. Irwin DE, Milsom I, Hunskaar S, Reilly K, Kopp Z, Herschorn S, et al. Population-based survey of urinary incontinence, overactive bladder, and other lower urinary tract symptoms in five countries: results of the EPIC study. Eur Urol. 2006;50:1306-14.

3. Irwin DE, Milsom I, Kopp Z, Abrams P, Artibani W, Herschorn S. Prevalence, severity, and symptom bother of lower urinary tract symptoms among men in the EPIC study: impact of overactive bladder. Eur Urol. 2009;56:14-20.

4. Wennberg AL, Molander U, Fall M, Edlund C, Peeker R, Milsom I. A longitudinal population-based survey of urinary incontinence, overactive bladder, and other lower urinary tract symptoms in women. Eur Urol. 2009;55:783-91.

5. Lawrence JM, Lukacz ES, Nager CW, Hsu JW, Luber KM. Prevalence and co-occurrence of pelvic floor disorders in community-dwelling women. Obstet Gynecol. 2008;111:678-85.

6. Currie CJ, McEwan P, Poole CD, Odeyemi IA, Datta SN, Morgan CL. The impact of the overactive bladder on health-related utility and quality of life. BJU Int. 2006:97:1267-72

7. Coyne KS, Sexton CC, Kopp ZS, Ebel-Bitoun C, Milsom I, Chapple C. The impact of overactive bladder on mental health, work productivity and health-related quality of life in the UK and Sweden: results from EpiLUTS. BJU Int. 2011;108:1459-71.

8. Patrick DL, Khalaf KM, Dmochowski R, Kowalski JW, Globe DR. Psychometric performance of the incontinence quality-of-life questionnaire among patients with overactive bladder and urinary incontinence. Clin Ther. 2013;35:836-45.

9. Bartoli S, Aguzzi G, Tarricone R. Impact on quality of life of urinary incontinence and overactive bladder: a systematic literature review. Urology. 2010;75:491-500

10. Coyne KS, Sexton CC, Irwin DE, Kopp ZS, Kelleher CJ, Milsom I. The impact of overactive bladder, incontinence and other lower urinary tract symptoms on quality of life, work productivity, sexuality and emotional well-being in men and women: results from the EPIC study. BJU Int. 2008;101:1388-95.

11. Sexton CC, Coyne KS, Vats V, Kopp ZS, Irwin DE, Wagner TH. Impact of overactive bladder on work productivity in the United States: results from EpiLUTS. Am J Manag Care. 2009;15:S98-S107.

12. National Institute for Clinical Excellence. Guide to the methods of technology appraisal. 2013. Ref Type: Generic

13. The EuroQol Group. EuroQol-a new facility for the measurement of health-related quality of life. Health Policy. 1990;16:199-208.

14. Brazier JE, Roberts J. The estimation of a preference-based measure of health from the SF-12. Med Care. 2004:42:851-9.

15. Yang Y, Brazier J, Tsuchiya A, Coyne K. Estimating a preference-based single index from the Overactive Bladder Questionnaire. Value Health. 2009;12:159-66.

16. Canadian Agency for Drugs and Technologies in Health. Guidelines for the economic evaluation of health technologies: Canada. 3rd ed. Otawa: Canadian Agency for Drugs and Technologies in Health; 2006.

17. Department of Economics and Public Health Assessment. Choices in Methods for Economic Evaluation: A methodological guide. Saint-Denis LA Plaine: Haute Autorité de Santé; 2012.

18. The AMCP Format for Formulary Submissions, version 2.1 A Format for Submissions of Clinical and Economic Data in Support of Formulary Consideration by Health Care Systems in United States. Academy of Managed Care Pharmacy (AMCP); 2005

19. Haywood KL, Garratt AM, Lall R, Smith JF, Lamb SE. EuroQol EQ-5D and condition-specific measures of health outcome in women with urinary incontinence: reliability, validity and responsiveness. Qual Life Res. 2008;17:475-83

20. Oh SJ, Ku JH. Is a generic quality of life instrument helpful for evaluating women with urinary incontinence? Qual Life Res. 2006;15:493-501.

21. Cuervo J, Castejon N, Khalaf K, Waweru C, Globe D, Patrick D. Development of the Incontinence Utility Index: estimating population-based utilities associated with urinary problems from the Incontinence Quality of Life Questionnaire and Neurogenic Module. Health and Quality of Life Outcomes. 2014;12:147.
22. Patrick DL, Martin ML, Bushnell DM, Yalcin I, Wagner TH, Buesching DP Quality of life of women with urinary incontinence: further development of the incontinence quality of life instrument (I-QOL). Urology. 1999;53:71-6.

23. Wagner TH, Patrick DL, Bavendam TG, Martin ML, Buesching DP. Quality of life of persons with urinary incontinence: development of a new measure. Urology. 1996:47:67-71.

24. Brazier JE, Rowen D, Mavranezouli I, Tsuchiya A, Young T, Yang Y, et al. Developing and testing methods for deriving preference-based measures of health from condition-specific measures (and other patient-based measures of outcome). Health Technol Assess. 2012;16:1-114.

25. Bushnell DM, Martin ML, Summers KH, Svihra J, Lionis C, Patrick DL. Quality of life of women with urinary incontinence: cross-cultural performance of 15 language versions of the I-QOL. Qual Life Res. 2005;14:1901-13.

26. Schurch B, Denys P, Kozma CM, Reese PR, Slaton T, Barron R. Reliability and validity of the Incontinence Quality of Life questionnaire in patients with neurogenic urinary incontinence. Arch Phys Med Rehabil. 2007:88:646-52.

27. Chapple C, Sievert KD, Macdiarmid S, Khullar V, Radziszewski P, Nardo C, et al. OnabotulinumtoxinA 100 U Significantly Improves All Idiopathic Overactive Bladder Symptoms and Quality of Life in Patients with Overactive Bladder and Urinary Incontinence: A Randomised, Double-Blind, Placebo-Controlled Trial. Eur Urol. 2013;64:249-56.

28. Nitti W, Dmochowski R, Herschorn S, Sand P, Thompson C, Nardo C, et al. OnabotulinumtoxinA for the treatment of patients with overactive bladder and urinary incontinence: results of a phase 3, randomized, placebo controlled trial. J Urol. 2013;189:2186-93.

29. Cruz F, Herschorn S, Aliotta P, Brin M, Thompson C, Lam W, et al. Efficacy and safety of onabotulinumtoxinA in patients with urinary incontinence due to neurogenic detrusor overactivity: a randomised, double-blind, placebo-controlled trial. Eur Urol. 2011;60:742-50.

30. Ginsberg D, Gousse A, Keppenne V, Sievert KD, Thompson C, Lam W, et al. Phase 3 efficacy and tolerability study of onabotulinumtoxinA for urinary incontinence from neurogenic detrusor overactivity. J Urol. 2012;187:2131-9.

31. Colman S, Chapple C, Nitti V, Haag-Molkenteller C, Hastedt C, Massow U. Validation of treatment benefit scale for assessing subjective outcomes in treatment of overactive bladder. Urology. 2008;72:803-7.

32. Ware Jr J, Kosinski M, Keller SD. A 12-Item Short-Form Health Survey: construction of scales and preliminary tests of reliability and validity. Med Care. 1996:34:220-33.

33. Gandek B, Ware JE, Aaronson NK, Apolone G, Bjorner JB, Brazier JE, et al. Cross-validation of item selection and scoring for the SF-12 Health Survey in nine countries: results from the IQOLA Project. International Quality of Life Assessment. J Clin Epidemiol. 1998;51:1171-8.

34. Brazier J. The Short-Form 36 (SF-36) Health Survey and its use in pharmacoeconomic evaluation. Pharmacoeconomics. 1995;7:403-15

35. Cunillera O, Tresserras R, Rajmil L, Vilagut G, Brugulat $P$, Herdman M, et al. Discriminative capacity of the EQ-5D, SF-6D, and SF-12 as measures of health status in population health survey. Qual Life Res. 2010;19:853-64.

36. Fryback DG, Dunham NC, Palta M, Hanmer J, Buechner J, Cherepanov D, et al. US norms for six generic health-related quality-of-life indexes from the National Health Measurement study. Med Care. 2007;45:1162-70.

37. Kelleher CJ, Cardozo LD, Khullar V , Salvatore S. A new questionnaire to assess the quality of life of urinary incontinent women. Br J Obstet Gynaecol. 1997;104:1374-9.

38. Brazier J, Czoski-Murray C, Roberts J, Brown M, Symonds T, Kelleher C. Estimation of a preference-based index from a condition-specific measure: the King's Health Questionnaire. Med Decis Making. 2008;28:113-26.

39. Wright B, Masters G. Rating Scale Analysis. Rasch Measurement. Chicago: MESA Press; 1982

40. Luppescu S. DIF detection examined. Rasch Measurement Transactions. 1993;7:285-6.

41. Nunnally J, Bernstein I. Psychometric theory. 3rd ed. New York: McGraw-Hill; 1994.

42. Campbell JD, Gries KS, Watanabe JH, Ravelo A, Dmochowski RR, Sullivan SD. Treatment success for overactive bladder with urinary urge incontinence refractory to oral antimuscarinics: a review of published evidence. BMC Urol. 2009:\%20:9:18-9. doi:10.1186/1471-2490-9-18.

43. Cohen J. Statistical power analysis for the behavioral sciences. 2nd ed Hillsdale: Lawrence Earlbaum Associates Inc.; 1988.

44. Pickard AS, Neary MP, Cella D. Estimation of minimally important differences in EQ-5D utility and VAS scores in cancer. Health Qual Life Outcomes. 2007;5:70. 
45. Walters SJ, Brazier JE. Comparison of the minimally important difference for two health state utility measures: EQ-5D and SF-6D. Qual Life Res. 2005; 14:1523-32

46. Yalcin I, Patrick DL, Summers K, Kinchen K, Bump RC. Minimal clinically important differences in Incontinence Quality-of-Life scores in stress urinary incontinence. Urology. 2006;67:1304-8.

47. Pinto AM, Kuppermann M, Nakagawa S, Vittinghoff E, Wing RR, Kusek JW, et al. Comparison and correlates of three preference-based health-related quality-of-life measures among overweight and obese women with urinary incontinence. Qual Life Res. 2011;20:1655-62.

48. Conner-Spady B, Suarez-Almazor ME. Variation in the estimation of quality-adjusted life-years by different preference-based instruments. Med Care. 2003:41:791-801.

49. O'Brien BJ, Spath M, Blackhouse G, Severens JL, Dorian P, Brazier J. A view from the bridge: agreement between the SF-6D utility algorithm and the Health Utilities Index. Health Econ. 2003;12:975-81.

50. Franks $P$, Hanmer J, Fryback DG. Relative disutilities of 47 risk factors and conditions assessed with seven preference-based health status measures in a national U.S. sample: toward consistency in cost-effectiveness analyses. Med Care. 2006;44:478-85.

51. Souchek J, Byrne MM, Kelly PA, O' Malley K, Richardson M, Pak C, et al. Valuation of arthritis health states across ethnic groups and between patients and community members. Med Care. 2005;43:921-8.

52. Lieu TA, Ortega-Sanchez I, Ray GT, Rusinak D, Yih WK, Choo PW, et al. Community and patient values for preventing herpes zoster. Pharmacoeconomics. 2008:26:235-49.

53. Brazier J. Valuing health States for use in cost-effectiveness analysis. Pharmacoeconomics. 2008;26:769-79.

\section{Submit your next manuscript to BioMed Central and take full advantage of:}

- Convenient online submission

- Thorough peer review

- No space constraints or color figure charges

- Immediate publication on acceptance

- Inclusion in PubMed, CAS, Scopus and Google Scholar

- Research which is freely available for redistribution 